\title{
O CONFLITO TÂMIL NO SRI LANKA: PAZ APÓS 10 ANOS DA VITÓRIA MILITAR?
}

\section{Tamil conflict in Sri Lanka: peace after 10 years of military victory?}

\author{
Geraldine Rosas Duarte ${ }^{1}$ \\ Matheus de Abreu Costa Souza ${ }^{2}$
}

\section{Introdução}

Em maio de 2009 o conflito separatista no Sri Lanka, que se arrastava desde 1986, chegou ao fim por meio de uma vitória militar do governo cingalês em relação aos Tigres de Libertação da Pátria Tâmil (LTTE). Após a derrota dos insurgentes e a execução das principais lideranças do grupo, muito se questionou em relação a como essa vitória militar poderia ser transformada num processo verdadeiro de resolução do conflito e promoção da paz. Como a literatura dos estudos de paz aponta, vitórias militares garantem o fim das hostilidades, mas não asseguram um tratamento profundo das causas que geraram o conflito, de modo que podem não ser determinantes na construção da paz de longo prazo.

Tendo isso em vista, este trabalho pretende analisar a situação atual do Sri Lanka, no que diz respeito à relação entre o governo central e a minoria tâmil, a fim de discutir os desdobramentos da vitória militar para a promoção da paz nos últimos dez anos. A hipótese aqui investigada é a de que a ausência de um processo de resolução de conflitos negociado, e não imposto por uma vitória militar, contribui para que as demandas da população tâmil, bem como o sentimento de marginalização desse grupo, continuem caracterizando o cenário pós-conflito no país. Investigar essa questão é de extrema relevância por duas principais razões. Em primeiro lugar, o ano de 2019, além de representar os 10 anos do fim do conflito no Sri Lanka, também evidenciou a manutenção de diversas tensões étnicas no país, o que demonstra que o Sri Lanka continua a ser um território propenso a crises políticas e sociais. Em segundo lugar, a literatura sobre paz e conflitos tende a focar em estudos sobre conflitos armados em andamento. Porém, este artigo busca evidenciar a relevância de que mesmo após a finalização formal da violência, tensões cotidianas entre grupos historicamente rivais tendem

\footnotetext{
${ }^{1}$ Professora do Departamento de Relações Internacionais e Programa de Pós-Graduação (PPGRI) da Pontifícia Universidade Católica de Minas Gerais (PUC Minas), doutora em Geografia e mestre em Relações Internacionais pela mesma instituição e graduada em Relações Internacionais pelo Centro Universitário de Belo Horizonte (UniBH). Email: geraldi-ne_rosas@hotmail.com

${ }^{2}$ Professor temporário na Pontifícia Universidade Católica de Minas Gerais (PUC Minas). Mestre em Relações Internacionais pela PUC Minas e Bacharel em Relações Internacionais pela mesma instituição. Email: matheusdeacsouza@gmail.com
} 
a se manter, sobretudo em casos de vitórias militares, que resultam em uma separação das partes beligerantes entre "vencedores" e "perdedores" do conflito, representados no Sri Lanka, respectivamente, pelo governo e pela população tâmil.

Desse modo, buscando realizar uma análise conjuntural sobre a situação do conflito tâmil dez anos após a vitória militar conquistada pelo governo do Sri Lanka, o texto estará dividido em três partes centrais, seguidas de considerações finais. A primeira delas traça uma breve contextualização histórica sobre o conflito separatista, enviando as causas principais da insatisfação da minoria tâmil e as diversas tentativas de resolução, todas elas fracassadas. A seção seguinte discute abordagens teóricas que problematizam as vitórias militares a partir de uma perspectiva da resolução de conflitos e da construção da paz de longo prazo. Por último, analisa-se o período de 2009 a 2019, refletindo sobre as fragilidades da paz que vem sendo construída no país. Em termos metodológicos, trata-se de um estudo de caso e o trabalho se assenta numa abordagem essencialmente dedutiva e qualitativa, utilizando análise de conteúdo e pesquisa bibliográfica e documental como técnicas centrais.

\section{Separatismo tâmil: décadas de conflito e a derrota militar}

A ilha do Sri Lanka foi colonizada, desde o início do século XVI, por portugueses, holandeses e, de forma mais expressiva, pelos ingleses, a partir do final do século XVIII. Para fortalecer o sistema de plantation estabelecido pelos colonizadores britânicos, tâmeis indianos foram trazidos do sul da Índia para o então Ceilão, que já contava com uma população dividida entre cingaleses e tâmeis. A independência do país foi conquistada em 1948 e, imediatamente, começaram a ser adotadas políticas discriminatórias em relação aos tâmeis. A primeira delas, conhecida como Ato de Cidadania, impediu que os mais de um milhão de tâmeis indianos tivessem direito à cidadania no país. Ao longo da década de 1950, outras medidas, como o Ato da Língua Oficial (Sihala Only), que decretou o cingalês como único idioma oficial, agravaram o sentimento de marginalização da população tâmil, culminando em diversos protestos e revoltas (FERNANDO, 2005).

As décadas de 1960 e 1970 foram marcadas por divergências políticas entre partidos tâmeis e cingaleses e por novas políticas discriminatórias. Em 1967, por exemplo, o governo introduziu cotas para admissão nas universidades que restringiam as possibilidades de ingresso para a população tâmil. Em 1972, uma nova Constituição foi promulgada, estabelecendo a República do Sri Lanka e favorecendo a população cingalesa, além de reafirmar a centralidade política por não conter elementos de federalismo. Nesse momento, como sinal da insatisfação crescente dos tâmeis, surgiram vários grupos insurgentes, sendo o mais forte e organizado deles os Tigres de Libertação da Pátria Tâmil (LTTE, sigla em inglês) (ABEYRATNE, 2004; DEVOTA, 2005).

As divergências políticas e as ondas de violência entre tâmeis e cingaleses chegaram ao seu ápice na primeira metade da década de 1980, forjando o separatismo tâmil, manifesto na busca pela independência das porções norte e leste da ilha, em função da crescente realidade de marginalização política, econômica e social do povo tâmil. O episódio que marcou o início da violência em larga escala no Sri Lanka é conhecido como Black July, quando, em julho de 1983, em resposta a uma emboscada organizada pelo LTTE, que matou 13 
soldados, um massacre contra a população tâmil resultou em mais de 3 mil mortos e cerca de 150 mil refugiados (GUNARATNA, 1997). Como aponta Sumatra Bose (2002), antes disso a insurgência tâmil operava por meio de ataques esporádicos, perpetrados por pequenos grupos de guerrilheiros. Poucos anos depois, o LTTE já contava com milhares de combatentes treinados e equipados, passando, gradativamente, a exercer um controle de facto de diversas províncias do norte e leste do país, o que só fez aumentar o desejo pela independência.

Diversas tentativas de paz ocorreram nos anos seguintes, sem grande sucesso. A Índia, por exemplo, enviou ao Sri Lanka uma força de manutenção de paz que deveria auxiliar na implementação de um acordo de paz estabelecido entre os dois países. Contudo, o LTTE não esteve envolvido nas negociações e, em função disso, obviamente, não se comprometeu com os termos. Inúmeras tentativas de negociação e de acordos de cessar-fogo ocorreram ao longo dos anos 1990, mas não houve avanços e as hostilidades continuaram.

Em fevereiro de 2000 a Noruega se propôs a mediar as conversações de paz entre o governo cingalês e os insurgentes tâmeis e, exatamente dois anos depois, esses esforços resultaram na assinatura de um acordo de cessar-fogo que criaria um ambiente favorável para as negociações de um acordo de paz. O LTTE se comprometeu com um processo de desarmamento, os dois lados trocaram prisioneiros de guerra e concordaram que a proposta de paz deveria estar baseada na autonomia política das províncias tâmeis. Em apoio ao processo de paz, o país recebeu cerca de U\$4,5 bilhões em doações, mas o LTTE, em meados de 2003, afirmou que os recursos estavam sendo monopolizados pelo governo enquanto os tâmeis continuavam sendo marginalizados (UYANGODA, 2005).

As negociações, a partir daí, ficaram estagnadas e em 2004 a ilha foi atingida por um grave tsunami, agravando a situação social das regiões norte e leste. Em 2005 a violência ressurgiu, colocando fim aos avanços em direção à paz. No início de 2008, oficialmente, o governo cingalês abandonou o processo de paz e lançou uma ofensiva para a retomada do controle das áreas ocupadas pelos Tigres do Tâmil. Essa ofensiva militar foi bem-sucedida, diante da dificuldade dos insurgentes de mobilizarem recursos internacionalmente, e em cerca de um ano e meio as forças cingalesas conseguiram recuperar áreas importantes, controladas há anos pelo LTTE. Em maio de 2009, o líder dos Tigres, Velupillai Prabhakaran, foi morto em combate, na retomada de um dos últimos redutos do LTTE, no norte da ilha (SRI LANKA PROFILE..., 2019).

A vitória militar obtida pelo governo cingalês desarticulou o grupo insurgente e colocou fim ao conflito separatista que durou quase três décadas, muito embora isso não tenha significado que as demandas tâmeis por autonomia e condições políticas, econômicas e sociais mais igualitárias tenham sido atendidas, como será demonstrado adiante. Estima-se que, entre 2005 e 2009, cerca de 20 mil insurgentes tenham sido mortos. Os impactos da ofensiva militar para a população civil localizada no norte e leste da ilha também não foram pequenos. Acredita-se que ao longo do ano de 2009, por exemplo, aproximadamente 8 mil civis tenham perdido a vida como consequência dos enfrentamentos. Quase 300 mil tâmeis se tornaram deslocados internos e milhares deixaram a ilha, aumentando ainda mais os números da já volumosa diáspora tâmil (AKHTAR, 2010). 


\section{As vitórias militares e suas implicações para a construção da paz}

Seguindo a sua prerrogativa normativa e pragmática, os estudos de paz visam refletir sobre formas de promover a transição de uma sociedade violenta para uma sociedade não-violenta (RAMSBOTHAM, WOODHOUSE e MIALL, 2011). Peter Wallensteen (2007) observa que um “[...] conflito existe, de acordo com as partes, pois existem queixas particulares e, assim, o conflito não pode terminar até que essas queixas sejam resolvidas, terminadas ou pelo menos atendidas" (WALLENSTEEN, 2007, p. 24, tradução nossa ${ }^{3}$ ). Logo, a resolução efetiva de um conflito depende de uma transformação na estrutura social, alcançada pelo combate exaustivo das insatisfações, que servem como base para a ascensão de grupos armados não-estatais. A resolução demanda, então, o estabelecimento de um arranjo pacífico que delimita as formas práticas nas quais os variados interesses dos beligerantes serão acomodados em um cenário de superação da violência (BROWN, 1996; WALLENSTEEN, 2007; DEROUEN JR., 2014; KALDOR, 2012; RAMSBOTHAM, WOODHOUSE e MIALL, 2011).

Levando em consideração a demanda por separação defendida pelo LTTE, a análise conjuntural aqui proposta foca no término de conflitos internos de natureza separatista, definidos aqui como "[...] um confronto armado entre um Estado independente soberano e um movimento de base regional, buscando romper ou buscando uma forma estendida de autogoverno territorial interno" (HERACLIDES, 1997, p. 682, tradução nossa ${ }^{4}$. Nessa modalidade de conflitos, as queixas intergrupais estão relacionadas a uma marginalização de um grupo, espacialmente localizado, por parte do Estado nacional; à exclusão histórica na esfera política, econômica, social e cultural; à ligação com a parcela territorial na qual o grupo se localiza; dentre outras (WALLENSTEEN, 2007; BROWN, 1996). Assim, o processo de transformação de conflitos separatistas depende necessariamente de uma negociação que contemple essas contradições que serviram como gatilho para a deflagração da violência por parte do grupo minoritário historicamente negligenciado pelo Estado nacional (WALLENSTEEN, 2007).

Porém, a despeito da diretriz normativa dos estudos sobre a paz, o término dos conflitos não acompanha necessariamente o estabelecimento de um acordo de paz que contemple as causas dos conflitos internos. Na verdade, pesquisas apontam que estes são geralmente terminados por vitórias militares, que representam a superação armada do adversário, aspecto que marca o término de tais guerras sobretudo até 2009 (FEARON; LAITIN, 2007; WALTER, 2002; HERACLIDES, 1997). De 2009 em diante, identifica-se uma tentativa maior de resolução dos conflitos internos por meio do estabelecimento de arranjos de paz compreensivos (KOVACS; SVENSSON, 2013).

Mais especificamente no caso de conflitos separatistas, Alexis Heraclides (1997) ressalta que o término do conflito tende a estar relacionado a uma negociação da paz pelos beligerantes ${ }^{5}$. Embora parte dos

\footnotetext{
3 “Conflict exists, parties will say, because there are particular grievances and, thus, the conflict cannot end until such grievances are resolved, ended or at least attended to".

4 "[...] an armed confrontation between a sovereign independent state and a regionally-based movement seeking to break away or seeking an extended form of internal territorial self-rule”

${ }^{5} \mathrm{Na}$ perspectiva do autor, doze aspectos contribuem para o término negociado de tais conflitos armados, que são: (1) ausência de perspectiva de vitória militar; (2) altos custos para a manutenção da luta armada; (3) acordo de paz provê um melhor cálculo custobenefício; (4) exaustão econômica e militar; (5) transformações contextuais, como a mudança de lideranças e mudanças no regime político; (6) Estado em vantagem militar, mas aproveita a situação para negociar com o grupo armado; (7) perda de apoio político ou militar externo; (8) negação de anexação por parte de territórios vizinhos; (9) mediação de atores não-estatais; (10) mediação coercitiva
} 
conflitos separatistas sejam resolvidos por uma via pacífica, Heraclides (1997) reconhece que em alguns casos as guerras são abruptamente terminadas por meio de vitórias militares, ou seja, quando há uma preparação estratégica e militar que consegue, por meio da coerção, superar o adversário por meio de enfrentamentos violentos diretos. Contudo, as vitórias militares não estão em conformidade com os processos de resolução de conflitos, como apontado por Mimmi Kovacs e Isak Svensson (2013), por se tratarem de imposições unilaterais da parte beligerante mais forte - geralmente o Estado nacional. Dessa forma, as vitórias militares não atendem à proposição de Wallensteen (2007), que gira em torno da finalização de conflitos por meio de acordos de paz que geram um compromisso formal entre as partes para tratar as causas que uma vez motivaram a utilização indiscriminada da violência.

Em argumento similar, Heraclides (1997) se posiciona contrariamente ao caráter impositivo característico das vitórias militares e expõe duas principais vantagens do estabelecimento dos acordos de paz negociados. Primeiro, o autor menciona que realizar concessões para o grupo separatista, relacionadas à autonomia e compartilhamento de poder, reduzem a possibilidade de recorrência à violência futura, na medida em que os interesses dos beligerantes seriam minimamente satisfeitos pelo acordo de paz no contexto pós-violência. Segundo, do ponto de vista humanitário, a implementação de estratégias que visam a vitória militar aumenta as chances de ocorrência de sucessivos abusos aos direitos humanos, que podem levar, inclusive, à atos de genocídio e limpezas étnicas contra a parcela da população que reivindica a separação/autonomia.

É válido ressaltar que na literatura que discute o término de conflitos e guerras, não há consenso se estratégias militares são mais ou menos eficazes em manter a paz pós-conflito quando comparados aos cenários em que há o estabelecimento de acordos negociados. Kovacs e Svensson (2013), contestam parte da literatura que defende a efetividade das vitórias militares em evitar o ressurgimento dos conflitos internos. Ao denunciar algumas falhas na codificação de dados utilizados para formulação de tais argumentos, Kovacs e Svensson (2013) demonstram que os acordos negociados conjuntamente pelas partes beligerantes tendem a garantir uma maior inclusão no processo de pacificação, além de facilitar o processo de democratização após o fim da violência, aspectos estes que levam à uma maior probabilidade de uma paz mais estável em tais cenários.

Em um argumento similar, Höglund e Kovacs (2010) afirmam que a forma na qual uma guerra é terminada afeta diretamente o tipo de paz estabelecido após o fim da violência. No caso de vitórias militares, as autoras argumentam que quando o governo é capaz de se impor sob o grupo rebelde, estes são exterminados - como em casos de limpeza étnica - ou são desmobilizados e forçadamente cooptados para o lado dos vencedores. Em contrapartida, em cenários em que a paz é negociada, “[...] antigos inimigos precisam encontrar uma forma de coexistirem" (HÖGLUND; KOVACS, 2010, p. 374, tradução livre6 ${ }^{6}$ ). Seguindo essa linha de argumentação, Höglund e Kovacs (2010) expõem que o término da violência física dentro de uma

para pressionar a assinatura de acordos; (11) assinatura prévia de um cessar-fogo e, por fim; (12) oferta de posições desejadas pelas lideranças do grupo separatista.

6 " $[. .$.$] former enemies have to find a way of co-existing".$ 
sociedade não garante necessariamente a resolução efetiva do conflito, na medida em que assuntos cruciais para as partes em conflito podem ter sido deixados de lado; arranjos políticos podem continuar a promover a marginalização cultural, social, econômica e política do grupo perdedor; e a violência pode continuar a fazer parte da rotina social, seja por enfrentamentos esporádicos entre perdedores insatisfeitos e vencedores, seja pela intensificação da violência criminal cotidiana, que é uma herança das economias ilícitas estabelecidas em contextos de guerra (HÖGLUND; KOVACS, 2010). Tendo em vista as variações da paz que podem existir dentro de uma sociedade após o fim formal de um conflito armado, a seção que segue buscará investigar as características da paz estabelecida no Sri Lanka após a vitória militar do governo que deu fim ao LTTE.

\section{O pós-conflito no Sri Lanka: problemas não resolvidos, marginalização e violência}

O objetivo da presente seção é compreender os impactos da vitória militar do governo do Sri Lanka sobre o LTTE. Desse modo, a análise conjuntural empregada levará em consideração três principais variáveis, consideradas na abordagem de Höglund e Kovacs (2010): (i) problemas não resolvidos; (ii) a possibilidade de manutenção da marginalização da parte perdedora e, por fim, (iii) a dinâmica de violência dentro da sociedade.

Conflitos separatistas, de acordo com Wallensteen (2007), tendem a ser resolvidos por meio da negociação de arranjos de compartilhamento de poder, de modo a proporcionar maior autonomia para o grupo não-estatal em uma determinada região. Nesse sentido, observando a categoria dos "problemas não resolvidos”, observa-se que no caso do Sri Lanka não houve avanços em direção à concessão de autonomia. A Constituição do Estado se manteve durante o período analisado, e a participação dos tâmeis na esfera política deveria ser restrita à capacidade do grupo de emplacar a vitória de parlamentares tâmeis em eleições distritais, previstas pela $13^{a}$ emenda constitucional, de 1987. A continuidade da estrutura de poder do Sri Lanka desagradou a minoria tâmil, motivando uma série de protestos e oposições de representantes da Aliança Nacional Tâmil (TNA) - grupo de coalizão tâmil - desde a vitória militar. A exemplo dessa insatisfação, podese citar as eleições parlamentares de julho de 2018, em que o TNA adotou uma retórica altamente nacionalista, levando membros de uma ala mais radical da coalizão a cogitarem, inclusive, o retorno do LTTE para lidar com os vetos à autonomia tâmil empregados pelo governo e alcançar a liberdade do grupo étnico ${ }^{7}$ (INTERNATIONAL CRISIS GROUP, 2019). Como a demanda principal do LTTE, relativa à concessão de autonomia ou separação, não foi adereçada em um acordo de paz no contexto pós-conflito, fica evidente que o processo de resolução não seguiu os pressupostos de tratamento efetivo das causas vistos em Heraclides (1997) e Wallensteen (2007), Kovacs e Svensson (2013). Sendo assim, considerando a mobilização recente de tal discurso, é possível inferir que a vitória militar do governo não foi capaz de eliminar a demanda tâmil por autonomia ou separatismo, e tal anseio ainda se faz presente mesmo após 10 anos do fim do conflito.

Em relação à marginalização da população tâmil, nota-se que, mesmo passados dez anos do fim do conflito, poucos avanços ocorreram. De acordo com os indicadores do Fragile States Index, muito embora a

\footnotetext{
${ }^{7}$ Nos anos de 2010, e de 2014 em diante, identifica-se que o TNA tem pressionado o governo nacional para a realização de uma reforma constitucional que garanta a autonomia do grupo étnico. Porém, o governo tem se esquivado de discutir a questão (INTERNATIONAL CRISIS GROUP, 2019).
} 
situação geral do país apresente uma melhora, especificamente no que tange às insatisfações de grupos sociais, poucas mudanças podem ser observadas. O indicador Group Grievance, que reflete um dos aspectos de coesão social, avalia divisões e segmentações entre os grupos sociais, considerando o acesso a recursos e serviços e a inclusão nos processos políticos do Estado. Desde 2009, quando o valor atribuído a esse indicador era 9,8, pouco se alterou. Em 2019 esse valor é 9,0, o que indica que a realidade no país continua crítica ${ }^{8}$ (FRAGILE STATES INDEX, 2019).

Tabela 1 - Group Grievance - Sri Lanka

\begin{tabular}{|c|c|c|c|c|c|c|c|c|c|c|}
\hline $\mathbf{2 0 0 9}$ & $\mathbf{2 0 1 0}$ & $\mathbf{2 0 1 1}$ & $\mathbf{2 0 1 2}$ & $\mathbf{2 0 1 3}$ & $\mathbf{2 0 1 4}$ & $\mathbf{2 0 1 5}$ & $\mathbf{2 0 1 6}$ & $\mathbf{2 0 1 7}$ & $\mathbf{2 0 1 8}$ & $\mathbf{2 0 1 9}$ \\
\hline 2,8 & 9,6 & 9,4 & 9,1 & 9,5 & 9,3 & 9,3 & 9,2 & 9,0 & 8,7 & 9,0 \\
\hline
\end{tabular}

Fonte: elaboração própria com base em FRAGILE STATES INDEX (2019).

Um dos aspectos relacionados a essa insatisfação diz respeito à impunidade associada à fase pósconflito, uma vez que não houve grande esforço por parte do governo no sentido de promover justiça em relação aos crimes e à violência cometidos durante os anos de guerra. Em 2010, foi criada uma Comissão de Reconciliação, indicada pelo presidente Mahinda Rajapaksa, para investigar as causas do fracasso da tentativa de cessar-fogo de 2002, as lições aprendidas pelos eventos que se sucederam e as medidas necessárias para promover a unidade e a reconciliação entre as comunidades do país. Após um trabalho de 18 meses, foi publicado o resultado das investigações, o Lessons Learnt and Reconciliation Comission Report, um relatório que isentou o governo cingalês e o exército do Sri Lanka dos crimes de guerra, enquanto acusou os Tigres do Tâmil de repetidamente terem violado o Direito Internacional Humanitário (DIH) (THE NATIONAL PEACE COUCIL OF SRI LANKA, 2019). Além desta iniciativa não ter produzido na população tâmil um sentimento de justiça, os anos seguintes à vitória militar foram marcados por muitos desaparecimentos de ex-combatentes do LTTE que haviam se rendido às forças armadas do Sri Lanka. O ano de 2017, em particular, foi caracterizado por diversas ondas de protestos motivados pela impunidade e pela falta de informações a esse respeito (SRI LANKA BRIEF, 2019). Nota-se, então, que o contexto pós-conflito no Sri Lanka enraíza a relação entre “vencedores” e "perdedores”, em que há uma excludente de ilicitude para aqueles que cometeram crimes em favor do governo durante o conflito, ao passo que os crimes cometidos pelos combatentes do LTTE foram enquadrados como violações ao DIH.

Outras formas de violência política e de discriminação contra a população tâmil também contribuíram para a insatisfação. Segundo dados do International Crisis Group (2019), em 2011, foram registrados casos de assassinatos e sequestros de tâmeis por parte de grupos paramilitares de apoio ao governo. As eleições locais de 2011, por exemplo, foram marcadas por altos índices de violência eleitoral propagada pelo exército nacional, de modo a coagir a população que apoiava o TNA à época. O mesmo ocorreu nas eleições provinciais que ocorreram na região norte do país em 2013, e nas eleições presidenciais de 2014. Em dezembro de 2012, a violência se fez presente mais uma vez na tensa relação entre tâmeis e exército nacional, quando estudantes

${ }^{8}$ Quando mais próximo de 10,0, mais grave é a realidade analisada. 
tâmeis foram enviados para centros de reabilitação por comemorarem publicamente o conflito. Prisões arbitrárias voltaram a ocorrer em janeiro de 2013, quando a polícia antiterrorista realizou uma série de ataques e interrogatórios contra políticos e ativistas tâmeis. Em maio de 2014, após uma ofensiva do governo contra os tâmeis, alegando um suposto ressurgimento do LTTE, a população tâmil foi proibida de celebrar os mártires da guerra, dentre outras medidas de cerceamento dos direitos tâmeis.

Mais recentemente, em agosto de 2019, o presidente cingalês, Maithripala Sirisena indicou Shavendra Silva como novo comandante do Exército. A decisão foi considerada pelos tâmeis e pela comunidade internacional como uma afronta e como uma tentativa de boicotar os esforços de reconciliação, uma vez que o Tenente-general é acusado de diversos crimes de guerra e violações aos direitos humanos durante o conflito. Nos meses finais do confronto, em 2009, Silva comandou uma divisão do exército cingalês apontada, pelo relatório do Escritório do Alto Comissário das Nações Unidas para os Direitos Humanos, como responsável por torturas, assassinatos, violência sexual e de gênero e ataques deliberados a instalações humanitárias, como hospitais (SRI LANKAN GENERAL..., 2019).

Outro fator determinante na insatisfação que continua caracterizando a população tâmil diz respeito à militarização do norte da ilha, bem como à questão dos deslocados internos. Durante os anos finais do conflito, milhares de tâmeis ficaram desabrigados e mais de 200 mil foram transferidos, forçadamente, para campos de deslocados (AKHTAR, 2010). Poucos meses após a vitória militar, a maior parte deles começou a ser reassentada em áreas devastadas pelas hostilidades, sem perspectivas de iniciativas de reconstrução. Nos anos seguintes, ao invés de se verificar um esforço nessa direção, o que vem sendo observado é um movimento de militarização e de ocupação, por cingaleses, de áreas tradicionalmente ocupadas pelos tâmeis, o que tem gerado protestos e crescentes reivindicações (INTERNATIONAL CRISIS GROUP, 2019).

De acordo com o relatório do The Oakland Institute (2015), em 2015 ainda haviam 36 campos de deslocados na região norte da ilha. O maior deles, o campo de Konadpulam, abrigava cerca de 800 pessoas e é base, também, de um acampamento militar. Embora não haja dados precisos a esse respeito, em 2012, estimava-se que $60 \%$ do exército cingalês estivesse estacionado na região norte do país. Segundo o Internal Displacement Monitoring Centre (2019), ainda existem aproximadamente 37 mil deslocados internos originados pelo conflito. A esperança de reassentamento desses deslocados e de reconstrução e recuperação das áreas ainda destruídas, no norte do país, residem, atualmente, nas atividades do Escritório de Reparações, estabelecido no final de outubro de 2018, como parte das medidas voltadas para a reconciliação nacional. Diante de tantos desafios e de um cenário profundo de insatisfações e ocorrência de atos violentos no país, resta saber se essas medidas conseguirão, de fato, construir uma paz duradoura no Sri Lanka.

Tendo em vista as causas mais enraizadas que geraram o conflito, há décadas atrás, mais especificamente as diversas políticas discriminatórias, a limitada representação política e a falta de autonomia para a região tâmil (GANGULY, 1996; ABEYRATNE, 2004; FERNANDO, 2005), o que se pode inferir acerca dos desdobramentos futuros é que o descontentamento da população tâmil persistirá, já que não se vê esforços governamentais no sentido de modificar a realidade marginalizada desse grupo. Sobretudo na 
ausência de uma oposição armada, as chances de que o governo cingalês faça concessões à autonomia e representação política tâmil é muito pequena.

A recente vitória nas eleições presidenciais, em novembro de 2019, de Gotabaya Rajapaksa, é mais um indicador de que as demandas tâmeis dificilmente serão acomodadas pelo governo central. Ele foi Secretário de Defesa durante o mandato do irmão, Mahinda Rajapksa (2005 - 2015), sendo considerado um dos grandes responsáveis pela vitória militar que derrotou o LTTE em 2009, colocando-o também como alvo de acusações pelas violações de direitos humanos e crimes de guerra cometidos no processo. Durante a campanha eleitoral, ele foi categórico ao afirmar que o Sri Lanka derrotará o terrorismo fundamentalista novamente, em referência aos atentados ocorridos na Páscoa, assim como o fez no passado (referindo-se ao LTTE) (GOTABAYA RAJAPKSA: SRI LANKA'S..., 2019). Ao que tudo indica, esse será um governo marcado pelo forte nacionalismo cingalês, o que em nada contribui para que os interesses tâmeis sejam atendidos. Naturalmente, isso não significa dizer que o conflito armado ressurgirá imediatamente ou que novos grupos insurgentes se mobilizarão, mas seguramente significa que as causas que produziram o nacionalismo e o separatismo tâmil permanecem existindo.

\section{Considerações finais}

A literatura sobre as vitórias e seus impactos no contexto pós-conflito se divide acerca da efetividade de tais vitórias em evitar o ressurgimento do conflito. A situação no Sri Lanka, até hoje, permanece inconclusiva no que tange a possibilidade de ressurgimento do conflito armado, haja vista que a sociedade ainda permanece polarizada, embora existam poucos enfrentamentos diretos entre tâmeis e tropas cingalesas. Porém, o que se pode afirmar até o momento é que a vitória militar, no caso do Sri Lanka, não promoveu a resolução efetiva das causas que motivaram tâmeis a se mobilizarem violentamente em favor do separatismo.

A não resolução do conflito fica em evidência quando se analisa as três categorias aqui discutidas. Ainda existem impasses não resolvidos no que tange a possibilidade de concessão de autonomia, o que levou grupos tâmeis a reivindicarem ativamente por tal demanda durante os últimos dez anos. Também foi demonstrado que a violência, embora muitas vezes manifesta de maneira indireta e esporádica, ainda faz parte da tensa relação entre as forças armadas e a população tâmil. Por fim, também fica em evidência que a minoria étnica seguiu às margens da sociedade no contexto pós-conflito, sobretudo quando se observa a marginalização das demandas por justiça levantadas em protestos, a ineficácia dos mecanismos de justiça transicional, a política de assentamentos em terras historicamente ocupadas pelos tâmeis e, por fim, a situação dos deslocados que ainda é grave. Nesse sentido, o Sri Lanka presencia atualmente uma paz frágil e instável, já que o contexto pós-conflito vem sendo marcado pela ineficácia em promover uma resolução efetiva, além da contínua polarização social dentro da sociedade cingalesa.

\section{REFERÊNCIAS}

ABEYRATNE, Sirimal. Economic roots of political conflict: the case of Sri Lanka. The World Economy, vol. 27, n. 8. 2004. 
AKHTAR, Shaheen. Managing ethnic conflict in Sri Lanka: going beyond the LTTE. In: WIRSING, R.; AHRARI, E. Fixing fractured nations: the challenge of ethnic separatism in the Asia Pacific. Palgrave Macmillan, 2010.

BOSE, Sumantra. Flawed mediation, chaotic implementation: the 1987 Indo-Sri Lanka Peace Agreement. In: STEDMAN, J.; ROTHCHILD, D.; COUSENS, E. Ending civil wars - the implementation of peace agreements. Boulder: Lynne Rienner Publishers, 2002.

BROWN, Michael E. (Ed.). The International Dimensions of Internal Conflict. Cambridge: MIT Press, 1996.

DEROUEN JR., Karl. An Introduction to Civil Wars. Thousand Oaks: CQ Press, 2015.

DEVOTA, Neil. From ethnic outbidding to ethnic conflict: the institutional bases for Sri Lanka's separatist war. Nations and Nationalism, v. 11, n. 1. 2005.

FEARON, James D.; LAITIN, David D. Civil war termination. Conference Paper, Annual Meetings of the American Political Science Association, Chicago, Illinois, 30 Agosto - 1 Setembro, 2007. Disponível em: <https://pdfs.semanticscholar.org/4894/e3a3ba9778117453f15c17cfbd9c6280cf47.pdf >. Acesso em 20 ago. 2019.

FERNANDO, Laksiri. Ethno-nationalism and youth dimension in the protracted social conflicts in Sri Lanka. International Relations in a Globalizing World, v.1, n.1. 2005.

FRAGILE STATES INDEX. Sri Lanka. Fund For Peace, Disponível em <https://fragilestatesindex.org/countrydata/>. Acesso em 20 set. 2019.

GANGULY, Sumit. Conflict and crisis in south and southeast Asia in: BROWN, Michael E.(ed.). The international dimensions of internal conflict. Cambridge: MIT Press.1996

GOTABAYA RAJAPKSA: SRI LANKA'S... Gotabaya Rajapaksa: Sri Lanka's powerful new president. BBC News. 25 de novembro de 2019. Disponível em <https:/www.bbc.com/news/world-asia50389014?intlink_from_url=https://www.bbc.com/news/topics/cywd23g0gxgt/srilanka\&link_location=live-reporting-story> Acesso em 28 nov. 2019.

GUNARATNA, Rohan. International and regional implications of the Sri Lankan Tamil insurgency. Bandaranaike Centre for International Studies. 1997. Disponível em <http://www.padippakam.com/document/srilankan_gov/gov002.pdf> Acesso em 20 nov. 2019.

HERACLIDES, Alexis. The Ending of Unending Conflicts: Separatist Wars. Millennium - Journal of International Studies, 1997, v. 26, n. 3, pp. 679-707.

HÖGLUND, Kristine; KOVACS, Mimmi S. Beyond the absence of war: the diversity of peace in post-settlement societies. Review of International Studies, v. 36, n. 2, Abril 2010, pp. 367-390.

INTERNATIONAL CRISIS GROUP. Crisis Watch Sri Lanka. International Crisis Group, 23 set. 2019. Disponível em: < https://www.crisisgroup.org/crisiswatch >. Acesso em: 23 set. 2019.

INTERNAL DISPLACEMENT MONITORING CENTRE. Sri Lanka: country information. Internal Displacement Monitoring Centre, 23 set. 2019. Disponível em <http://www.internaldisplacement.org/countries/sri-lanka >. Acesso em 23 set. 2019

KALDOR, Mary. New and Old Wars: Organized Violence in a Global Era. $3^{\mathrm{a}}$ ed. Cambridge: Polity Press, 2012.

KOVACS, Mimmi S.; SVENSSON, Isak. The Return of Victories? The Growing Trend of Militancy in Ending Armed Conflicts. Conference Paper, General Conference of the European Consortium for Political Research (ECPR), Science Po Bordeaux, 4-7 set. 2013. Disponível em: 
<http://ecpr.eu/Filestore/PaperProposal/8b5c9fb5-9173-47da-969f-28d8124cbc67.pdf>. Acesso em 20 ago. 2019.

RAMSBOTHAM, Oliver; WOODHOUSE, Tom; MIALL, Hugh. Contemporary Conflict Resolution: the Prevention, Management and Transformation of Deadly Conflicts. $3^{\text {a }}$ ed. Cambridge: Polity Press, 2011.

SRI LANKA PROFILE - TIMELINE. BBC News, 25 de abril de 2019. Disponível em <https://www.bbc.com/news/world-south-asia-12004081> Acesso em 13 ago. 2019

SRI LANKA BRIEF. Sri Lanka HR Reports. Disponível em <https://srilankabrief.org/sri-lanka-hr-reports/> Acesso em 23 set. 2019.

SRI LANKAN GENERAL... Sri Lankan general accused of war abuses appointed army chief. Al Jazeera. 19 ago 2019. Disponível em <https://www.aljazeera.com/news/2019/08/sri-lankan-general-accused-warabuses-appointed-army-chief-190819170119306.html> Acesso em 23 set. 2019.

THE NATIONAL PEACE COUCIL OF SRI LANKA. LLRC Official Version. Disponível em <https://www.peacesrilanka.org/media-centre/publications/item/92-llrc-official-version> Acesso em 23 set. 2019.

The Oakland Institute. The long shadow of war: the struggle for justice in postwar Sri Lanka. 2015. Disponível em <https://www.oaklandinstitute.org/long-shadow-war> Acesso em 23 set. 2019.

Uyangoda, J. Transition to civil war to peace: challenges of peace-building in Sri Lanka. Working Paper. Social Scientist Association. Colombo, 2005.

WALLENSTEEN, Peter. Understanding Conflict Resolution: War, Peace and the Global System. London: Sage Publications, 2007.

WALTER, Barbara F. Committing to Peace. Princeton: Princeton University Press, 2002.

Recebido em 5 de outubro de 2019. Aprovado em 03 de dezembro de 2019. 


\title{
RESUMO
}

Entre 1983 e 2009, o Sri Lanka presenciou um intenso conflito separatista envolvendo as forças armadas do governo e o grupo étnico tâmil, representados pelos Tigres de Libertação da Pátria Tâmil (LTTE). O conflito foi terminado forçadamente em 2009, após o sucesso de uma ofensiva militar lançada pelo governo, e, assim, nenhum acordo de paz foi assinado para selar a paz entre as partes. Desse modo, pretende-se elaborar uma análise conjuntural que discute os impactos da vitória militar para se pensar a relação atual entre o governo cingalês e a minoria étnica tâmil. Para tanto, foram mobilizados diversos relatórios de acompanhamento, que ressaltam avanços e retrocessos, na relação entre o governo do Sri Lanka e a minoria tâmeis entre maio de 2009 e setembro de 2019. As evidências aqui mobilizadas apontam para o fato de que a vitória militar não resultou em uma resolução efetiva do conflito, haja vista que os tâmeis não tiveram suas demandas por autonomia atendidas no momento pós-conflito, e, além disso, se mantiveram as tensões étnicas dentro do país, além da marginalização e repressão dos tâmeis no país.

Palavras-chave: Vitórias Militares; Conflitos Separatistas; Sri Lanka.

\begin{abstract}
Between 1983 and 2009, Sri Lanka witnessed an intense separatist conflict involving the government armed forces and the Tamil ethnic group, represented by the Liberation Tigers of Tamil Eelam (LTTE). The conflict forcibly ended in 2009 following the success of a government-launched military offensive, and therefore no peace agreement was signed to seal peace between the parties. Thus, we intend to elaborate an analysis that discusses the current impact of the military victory regarding the relationship between the Sri Lankan government and the Tamil ethnic minority. To do so, we resorted to a number of follow-up reports highlighting advances and setbacks in the relationship between the Sri Lankan government and the Tamil minority between May 2009 and September 2019. The evidence mobilized here points to the fact that military victory did not result in an effective resolution of the conflict, since the Tamils did not have their demands for autonomy met in the post-conflict context and, in addition, ethnic tensions remained within the country groups, as well as the marginalization and repression of Tamils in the country.
\end{abstract}

Key-words: Military Victories; Separatist Conflicts; Sri Lanka.

\section{COPYRIGHT:}

Este é um artigo publicado em acesso aberto e distribuído sob os termos da Licença de Atribuição Creative Commons, que permite uso irrestrito, distribuição e reprodução em qualquer meio, desde que o autor e a fonte originais sejam creditados.

This is an open-access article distributed under the terms of a Creative Commons Attribution License, which permits unrestricted use, distribution, and reproduction in any medium, provided that the original author and source are credited.

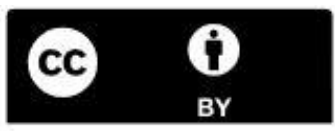

